\title{
MINIMIZAÇÃO DA EROSÃO EM FUNÇÃO DO TAMANHO E LOCALIZAÇÃO DAS ÁREAS DE FLORESTA NO CONTEXTO DO PROGRAMA “CONSERVADOR DAS ÁGUAS”(1)
}

\author{
Cornélio Alberto Zolin( ${ }^{(2)}$, Marcos Vinícius Folegatti( ${ }^{(3)}$, Rafael \\ Mingoti $^{(4)}$, Rodrigo Máximo Sánchez-Román ${ }^{(5)}$, Janaina Paulino ${ }^{(6)}$ \& \\ Alba Maria Guadalupe Orellana Gonzáles ${ }^{(7)}$
}

\begin{abstract}
RESUMO
Com os crescentes conflitos de uso da água no Brasil, a implantação de políticas para a mitigação desses problemas tornou-se crucial. Nesse sentido, o conceito de Pagamentos por Serviços Ambientais (PSA) tem se difundido ao redor do mundo e, consequentemente, no Brasil. O município de Extrema, em Minas Gerais, implantou a primeira iniciativa municipal brasileira de PSA, conhecida como programa "Conservador das Águas". Neste trabalho, objetivou-se avaliar a perda de solo na sub-bacia das Posses, onde se iniciou o programa "Conservador das Águas", visando determinar a potencialidade que o conceito adotado nesse programa terá para a conservação do solo e otimizar o provimento desse serviço ambiental em função do tamanho e da localização da área de floresta. Quatorze diferentes cenários de uso e cobertura do solo foram analisados, utilizando-se um Sistema de Informações Geográficas e a Revised Universal Soil Loss Equation. A expectativa de perda de solo na sub-bacia das Posses antes e após a implementação do programa “Conservador das Águas" foi de 30,63 e 7,06 $\mathrm{Mg} \mathrm{ha}^{-1} \mathrm{ano}^{-1}$, respectivamente. A otimização da conservação do solo pode ser feita adotando-se práticas conservacionistas na pastagem e alocando-se a área de floresta de maneira mais otimizada.
\end{abstract}

Termos de indexação: água, bacia hidrográfica, programa conservador das águas, sustentabilidade, conservação do solo, produção de sedimentos.

\footnotetext{
(1) Parte da Tese de Doutorado em Ciências, com ênfase em Irrigação e Drenagem, apresentada pelo primeiro autor à Universidade de São Paulo - ESALQ/USP. Recebido para publicação em 14 de abril de 2011 e aprovado em 13 de setembro de 2011.

2) Pesquisador da Embrapa Agrossilvipastoril, área de Manejo, Conservação e Uso de Recursos Hídricos. Caixa Postal 343 , CEP 78550-970 Sinop (MT). E-mail: cornelio.zolin@embrapa.br

(3) Eng.-Agr., Dr., Professor Titular do Departamento de Engenharia de Biossistemas, Universidade de São Paulo - Esalq/USP. Caixa Postal 09, CEP 13418-900 Piracicaba (SP). E-mail: mvfolega@esalq.usp.br

(4) Doutorando em Irrigação e Drenagem, Esalq/USP. E-mail: remingoti@uol.com.br

(5) Eng.-Agr., Dr., Professor do Departamento de Engenharia Rural, Universidade Estadual Paulista "Júlio de Mesquita Filho", Faculdade de Ciências Agronômica - UNESP/FCA. Caixa Postal 237, CEP 18610-307 Botucatu (SP). E-mail: rmsroman@fca.unesp.br

${ }^{(6)}$ Doutoranda em Irrigação e Drenagem, Esalq/USP. E-mail: jpaulino@esalq.usp.br

(7) Doutora em Ecologia Aplicada, Diretora Nacional de Pesquisa Científica e Tecnológica do Ministério da Educação de El Salvador. E-mail: alba.orellana@mined.gob.sv
} 


\title{
SUMMARY: SOIL LOSS MINIMIZATION AS A FUNCTION OF FOREST SIZE AND LOCATION IN A "WATER CONSERVATION PROGRAM"
}

\begin{abstract}
As conflicts related to the water use in Brazil are increasing, the implementation of policies that can mitigate these problems has become crucial. In this context, the concept of Payment for Environmental Services (PES) has been widely accepted and applied around the world and also in Brazil. The municipality of Extrema, in the State of Minas Gerais, was the first in Brazil to implement a PES program, known as "Conservador das Águas". This study aimed to evaluate soil losses in the watershed Posses and determine the potential of the PES program to conserve soil in this watershed; moreover, to maximize the soil conservation environmental service for a given forest size and location. Therefore, the effectiveness of soil conservation was analyzed in 14 areas with different soil use and forest cover. The Geographic Information System (SIG) and the Revised Universal Soil Loss Equation (RUSLE) were used for this purpose. Soil losses in the Posses watershed were estimated before and after implementing the water conservation program, at 30.63 and $7.06 \mathrm{Mg} \mathrm{ha}^{-1}$ year-1, respectively. Conservation could be optimized by implementing soil conservation practices on pasture and by optimizing the location of forest areas.
\end{abstract}

\section{Index terms: water, watershed, water conservation program, sustainability, soil conservation, sediment production.}

\section{INTRODUÇÃO}

Embora o Brasil seja o país mais bem dotado de reservas hídricas do planeta, estas, por sua vez, não estão distribuídas de acordo com a concentração das populações. Nem sempre onde ocorrem as maiores concentrações urbanas e altas demandas estão presentes as maiores porções dessas reservas hídricas, e isso causa sérios problemas em relação à manutenção do abastecimento das regiões mais populosas.

Bons exemplos dessa problemática são as bacias hidrográficas dos rios Piracicaba, Capivari e Jundiaí (BH-PCJ), de onde são transpostos $31 \mathrm{~m}^{3} \mathrm{~s}^{-1}$ para o abastecimento da Região Metropolitana de São Paulo (RMSP), comprometendo a disponibilidade hídrica nessas bacias.

Vários trabalhos, como os de Sánchez-Román et al. (2009a,b,c), Folegatti et al. (2010) e OrellanaGonzález et al. (2011), relacionados à problemática dos recursos hídricos nas BH-PCJ têm sido desenvolvidos visando auxiliar os tomadores de decisão no que concerne às possíveis políticas a serem implementadas para gestão dos recursos hídricos dessas bacias. Os referidos autores utilizaram a metodologia de Dinâmica de Sistemas para modelar o sistema de recursos hídricos das BH-PCJ e fornecer uma ferramenta para ser usada como subsídio pelos tomadores de decisão, bem como aplicaram diversos índices de sustentabilidade que permitiram realizar um diagnóstico da situação atual e um prognóstico futuro da sustentabilidade hídrica dessas bacias. Com a abordagem em Dinâmica de Sistemas, esses autores congregaram diversas variáveis preponderantes sobre a oferta e demanda de recursos hídricos das BH-PCJ (bem como o lançamento de resíduos pelos diferentes setores usuários), entre elas o crescimento populacional, os padrões sociais, o saneamento básico, as políticas públicas e a transposição para o Sistema Cantareira. Como conclusões, os autores verificaram que a situação atual das BH-PCJ é bastante crítica, pois a demanda de água está muito próxima a $100 \%$ da oferta. Eles concluíram também, com base nas simulações realizadas, que em longo prazo - se políticas eficazes não forem adotadas - as BH-PCJ enfrentarão uma crise crônica de escassez de água.

Folegatti et al. (2010) observam que nos casos como os das bacias PCJ e da RMSP, onde há um problema físico de escassez de água (quando os recursos hídricos não são suficientes para atender às demandas dos diferentes setores usuários), a mitigação dessa problemática terá de se fundamentar basicamente em políticas de gestão econômica, social e ambiental, que atendam a esse propósito.

Nesse contexto, recentemente, iniciativas importantes foram tomadas para tentar amenizar a escassez de água das BH-PCJ, como a implantação do conceito de Pagamentos por Serviços Ambientais (PSA), que visa à conservação do solo e da água nas cabeceiras dessas bacias. Essa iniciativa terá, consequentemente, efeitos importantes para o abastecimento da RMSP, uma vez que esta depende grandemente da transposição de $31 \mathrm{~m}^{3} \mathrm{~s}^{-1}$ das BHPCJ para seu abastecimento.

Essas iniciativas originaram-se no município de Extrema, em Minas Gerais, que criou, por meio da Lei Municipal $n^{\circ} 2.100$ de 21 de dezembro de 2005, o projeto "Conservador das Águas". Esse projeto é a primeira iniciativa municipal brasileira a implantar o conceito de PSA com base na relação entre a floresta e os serviços prestados por ela no tocante a conservação do solo, quantidade e qualidade de água e que visa à 
conservação dos recursos hídricos a serem utilizados pelo Sistema Cantareira, por meio da transposição das BH-PCJ.

Com o objetivo de implantar o conceito de PSA, a prefeitura de Extrema, juntamente com parceiros do projeto, compensa financeiramente proprietários rurais que se comprometam a aderir ao projeto "Conservador das Águas", por meio da execução de ações de proteção florestal e restauração de suas áreas degradadas que margeiam os cursos d'água, dentro da sub-bacia hidrográfica das Posses, inserida no município (Extrema, 2010).

Com a implantação do projeto e adoção das práticas nele propostas, têm-se como hipóteses: redução efetiva dos processos erosivos e, consequentemente, do transporte de sedimentos; aumento da vazão média do manancial ao longo do tempo; e melhoria ou manutenção da qualidade da água dos mananciais das sub-bacias hidrográficas de Extrema-MG.

Na sub-bacia das Posses (Figura 1), de acordo com Silva et al. (2008), o uso predominante do solo é a pastagem - utilizada basicamente para alimentação animal na pecuária leiteira. Essas pastagens, por sua vez, encontram-se em elevado grau de degradação, com baixa produção de biomassa e pouca cobertura do solo, favorecendo substancialmente os processos erosivos. Outro fator importante, segundo Silva et al. (2008), é que o relevo acidentado e a alta erodibilidade dos solos na sub-bacia das Posses agravam ainda mais esses processos.

Tão importante quanto a implementação de projetos/sistemas de PSA é a avaliação dessas iniciativas, de modo que se possa vislumbrar os serviços ambientais que podem ser efetivamente gerados. Nesse sentido, para otimizar o provimento de determinado serviço ambiental (por exemplo, a redução da perda de solo), é de fundamental importância que uma análise sistemática e integrada seja realizada
Nesse contexto, ao implantar projetos de PSA que contemplem práticas de reflorestamento para a conservação do solo (e consequentemente da água), é importante que se determine o tamanho e a localização para a cobertura florestal que maximize o provimento desse serviço ambiental. Num sentido mais econômico, uma vez que seja possível obter os mesmos resultados de redução de perda de solo com áreas menores de floresta, não há motivo (do ponto de vista de conservação do solo) para aumentar as áreas com cobertura florestal, uma vez que esse adicional poderia ser destinado às outras sub-bacias, onde poderiam proporcionar maiores benefícios, ou seja, maior retorno líquido (redução da perda de solo), em função do capital investido (área de floresta).

Embora existam vários trabalhos relacionados ao efeito do uso e cobertura do solo sobre a erosão (Fiorio et al., 2000; Souto \& Crestana, 2000; Galvão et al., 2005; Tomaz, 2007; Inácio et al., 2007; Weill \& Sparovek, 2008), os estudos sobre a influência do tamanho e da localização da cobertura vegetal, principalmente a florestal, conjuntamente com outras práticas de conservação, ainda são escassos.

Os trabalhos existentes, em grande parte, fazem uso da modelagem da erosão em sistemas de informação geográfica (SIG), devido à facilidade, rapidez e razoável precisão na comparação de diversos cenários de práticas conservacionistas (Pessoa et al., 1997) - entre elas, a implantação de cobertura florestal.

O SIG, por sua vez, vem sendo cada vez mais usado em estudos (científicos e não científicos) para embasar políticas públicas, como é o caso da saúde: alguns municípios brasileiros estão implantando um SIG especializado para gerenciar a área de recursos humanos em saúde (Perantoni \& Vianna, 2003). Outros exemplos podem ser encontrados nas políticas de ordenamento e zoneamento do uso do solo (Lisboa, 2008), que são de grande aplicação em trabalhos em SIG.

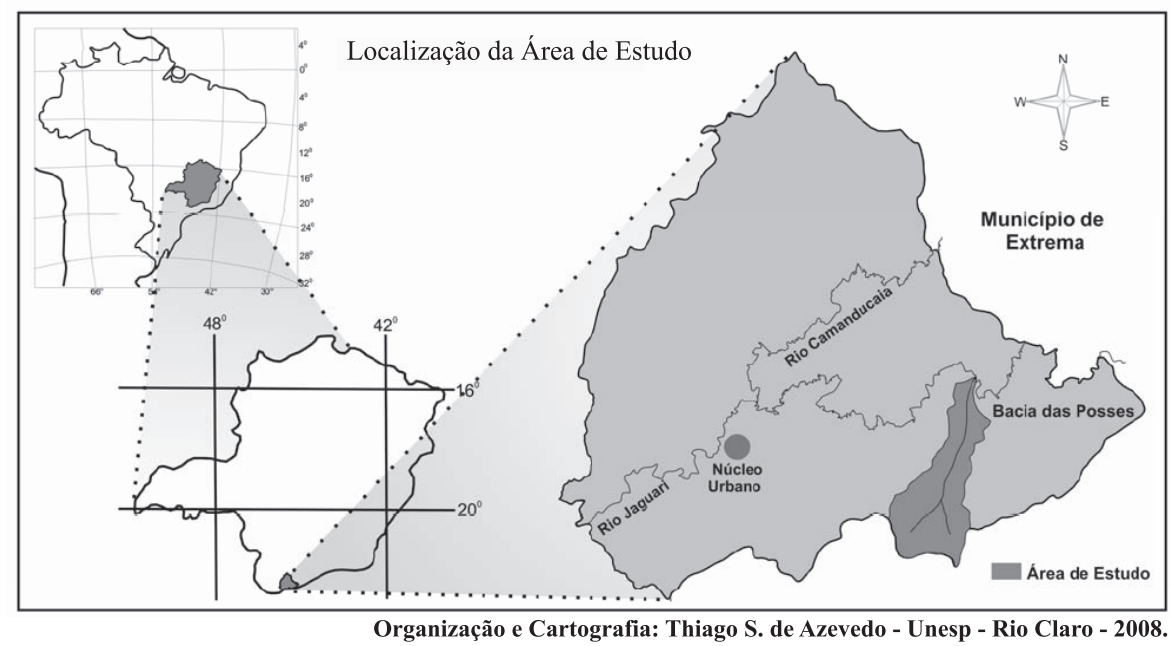

Figura 1. Localização geográfica da sub-bacia das Posses. Fonte: Azevedo (2008). 
Considerando a escassez de estudos que relacionem o tamanho e a localização da cobertura vegetal (especialmente a cobertura florestal) com a redução da perda de solo, e tendo em vista a importância do município de Extrema para o abastecimento de água das BH-PCJ e RMSP, bem como a necessidade de avaliação da efetividade dos programas de PSA, realizou-se o presente estudo com a utilização de um Sistema de Informações Geográficas, objetivando avaliar a perda de solo na sub-bacia das Posses e identificar cenários de uso e cobertura do solo que maximizem o provimento desse serviço ambiental, de modo a determinar a potencialidade que a adoção do conceito de PSA terá para a conservação do solo.

\section{MATERIAL E MÉTODOS}

Extrema é um dos quatro municípios mineiros que integram as BH-PCJ, e um dos principais contribuintes do Sistema Cantareira. A sub-bacia das Posses é uma das sete que compõem o município de Extrema, que se localiza na região sul do Estado de Minas Gerais, entre as coordenadas UTM ZONA 23K: 370.590 - 374.360E e 7.467.690 - 7.474.830N (Datum SIRGAS) e as altitudes de 1.144 a $1.739 \mathrm{~m}$. Possui 1.200 ha aproximadamente com relevo predominantemente ondulado e forte ondulado - cerca de $85 \%$ da área da sub-bacia; a área plana é praticamente desprezível, representando 0,7 \% (Silva et al., 2008).

$\mathrm{Na}$ área de estudo, predominam cinco tipos de solo (Figura 2): Neossolos Litólicos e Flúvicos, Cambissolos Háplicos e Húmicos e Argissolos Vermelho-Amarelos. Esses ambientes apresentam solos rasos com afloramentos de rochas que dificultam o preparo mecanizado do solo, sendo destinados apenas ao pastoreio com grandes restrições (Silva et al., 2008).

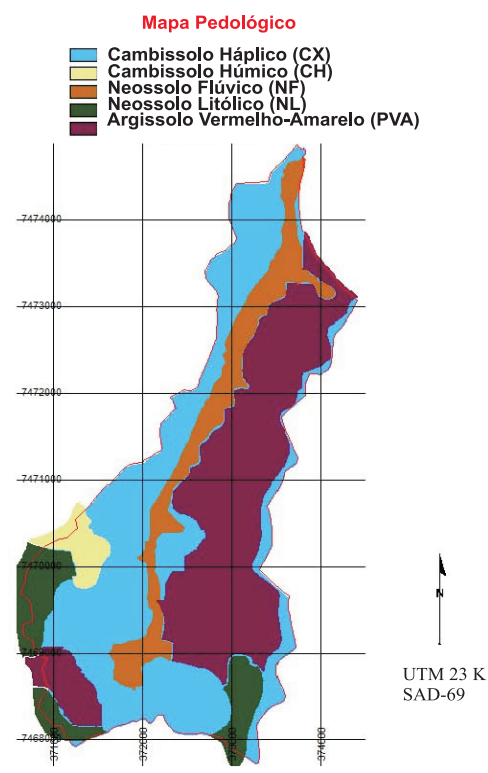

Figura 2. Distribuição das classes de solo da subbacia das Posses. Fonte: Silva et al. (2008).

Esses autores observam também que, devido à baixa infiltração de água, tendência ao encrostamento e pouca espessura dos solos, além de outras características, estes apresentam alta suscetibilidade à erosão.

Tendo como base a situação de uso e cobertura do solo da sub-bacia das Posses antes da implementação do projeto "Conservador das Águas" - Figura 3a (ano de 2005), bem como a situação futura de uso e cobertura após a implementação do projeto (Figura 3b), que contempla 50 nascentes protegidas, 150 ha de matas ciliares (APP), 280 ha de mata de "topo" (MT), 300 ha de reserva legal (RL), 1.200 ha de solos conservados e 100 propriedades com saneamento, foram formulados
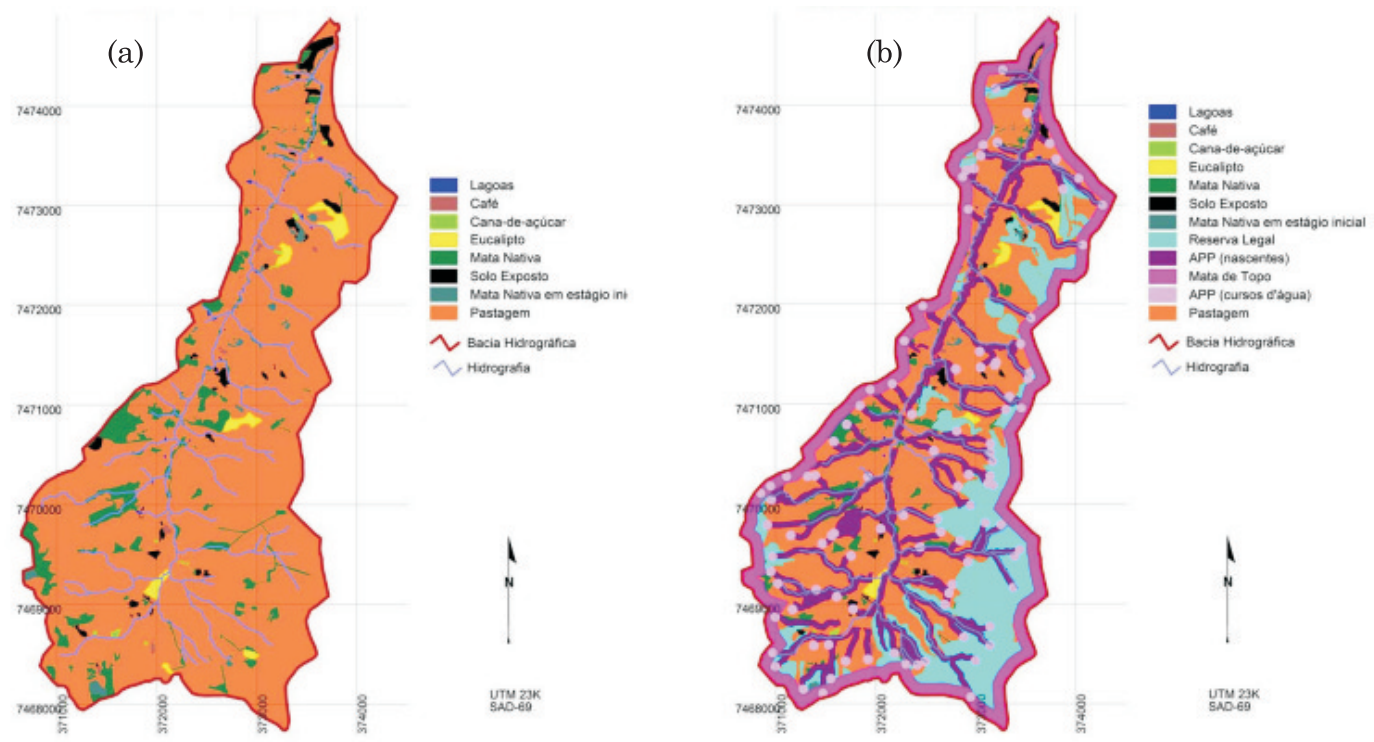

Figura 3. Tipos de uso do solo na sub-bacia das Posses, antes (a) e após (b) a implantação do projeto "Conservador das Águas". 
diferentes cenários com pastagem "degradada" e "conservada" e com diversos graus de cobertura do solo com floresta, analisando-se os seus efeitos sobre a redução de perda de solo.

Para analisar a efetividade das práticas implementadas no projeto, considerou-se para a pastagem as condições degradada e conservada; para a área de preservação permanente (APP) e reserva legal (RL), as condições de uso atual e futuro; e para a mata de topo (MT), as condições de uso atual, futuro e $50 \%$ da situação de uso futuro. As condições da pastagem degradada/conservada e uso atual e futuro do solo na sub-bacia das Posses referem-se, respectivamente, às condições antes e após a implantação das práticas conservacionistas previstas no projeto "Conservador das Águas". Além disso, visando alocar a floresta em função da declividade, consideraram-se duas situações distintas: a primeira levou em conta que as áreas da sub-bacia das Posses que possuíssem declives iguais ou superiores a $30 \%$ seriam destinadas ao reflorestamento com espécies florestais nativas; e, na segunda situação, foi utilizada a mesma analogia, porém desta vez considerou-se que as áreas destinadas ao reflorestamento com espécies florestais nativas teriam declividades iguais ou superiores a $40 \%$. A descrição de todos os cenários analisados encontra-se no quadro 1.

Para estimativa das perdas de solo por erosão, nos diferentes cenários estudados, utilizou-se a Revised Universal Soil Loss Equation - RUSLE (Renard et al., 1997), descrita na equação 1 , e o Sistema de Informação Geográfica (SIG) IDRISI Kilimanjaro.

$$
\mathrm{A}=\mathrm{R} \text { K LS CP }
$$

em que A é a perda média de solo anual, $\mathrm{Mg} \mathrm{ha}^{-1} \mathrm{ano}^{-1}$; $R$, a erosividade da chuva e da enxurrada a ela associada, MJ ha-1 $\mathrm{mm}^{-1} \mathrm{~h}^{-1} ; \mathrm{K}$, o fator de erodibilidade dos solos, $\mathrm{Mg} \mathrm{MJ}^{-1} \mathrm{~h}^{-1} \mathrm{~mm}^{-1}$; LS, o fator comprimento de rampa e percentagem do declive, adimensional; C, o fator de cobertura e manejo do solo, adimensional; e $\mathrm{P}$, o fator de práticas conservacionistas, adimensional.

Destaca-se aqui que os valores de perda de solo não foram confirmados em campo, o que também influencia nas conclusões do trabalho; no entanto, buscou-se propor uma forma de análise que otimize o provimento do serviço ambiental de conservação do solo em função do tamanho e alocação da área de floresta e avaliar de forma comparativa os diferentes cenários simulados, justificando assim o uso da RUSLE. Essa análise lança uma nova forma de se abordar o reflorestamento no contexto de uma bacia hidrográfica, quando se busca a redução da perda de solo.

Observa-se ainda que a "instrumentação" da subbacia das Posses para o monitoramento hidrológico e da conservação de solo já teve início, e isso possibilitará, em um futuro próximo, refinar as análises realizadas no presente trabalho, bem como trazer outras contribuições relevantes para o estudo e entendimento dos programas de PSA.

Para os fatores K e CP da RUSLE, adotaram-se, respectivamente, os valores sugeridos por Bertoni \& Lombardi Neto (1999) e os apresentados por Chaves et al. (2004).

No cálculo da erosividade das chuvas utilizou-se o método proposto por Bertoni \& Lombardi Neto (1999) e os dados de chuva mensal - para os períodos coincidentes de 1974 a 1993 - das estações pluviométricas próximas à sub-bacia das Posses, uma vez que séries históricas de precipitação são inexistentes na área de estudo. A relação das estações pluviométricas estudadas é apresentada no quadro 2.

Quadro 1. Caracterização dos cenários estudados, quanto a situação, tamanho e localização da cobertura do solo, na sub-bacia das Posses

\begin{tabular}{|c|c|c|c|c|}
\hline \multirow{2}{*}{ Cenário } & \multicolumn{4}{|c|}{ Situação } \\
\hline & Pastagem & APP e RL & MT & Declividade \\
\hline $1^{(1)}$ & Degradada & Atual & Atual & não \\
\hline 2 & Degradada & Futura & Futura & $\geq 30 \%$ \\
\hline 3 & Degradada & Futura & Futura & $\geq 40 \%$ \\
\hline 4 & Degradada & Futura & $50 \%$ Futura & não \\
\hline 5 & Conservada & Atual & Atual & não \\
\hline 6 & Conservada & Atual & Futura & $\geq 30 \%$ \\
\hline 7 & Conservada & Atual & Futura & $\geq 40 \%$ \\
\hline 8 & Conservada & Atual & $50 \%$ Futura & $\geq 30 \%$ \\
\hline 9 & Conservada & Futura & Atual & $\geq 30 \%$ \\
\hline $10^{(1)}$ & Conservada & Futura & Futura & não \\
\hline 11 & Conservada & Futura & Futura & $\geq 30 \%$ \\
\hline 12 & Conservada & Futura & Futura & $\geq 40 \%$ \\
\hline 13 & Conservada & Futura & $50 \%$ Futura & não \\
\hline 14 & Conservada & Futura & $50 \%$ Futura & $\geq 40 \%$ \\
\hline
\end{tabular}

\footnotetext{
(1) Os cenários 1 e 10 são, respectivamente, a situação de uso e cobertura do solo antes e após a implantação do projeto "Conser-
} vador das Águas"; APP: Área de Preservação Permanente; RL: Reserva Legal; MT: Mata de Topo. 
Quadro 2. Relação das estações pluviométricas utilizadas

\begin{tabular}{clcc}
\hline Estação Pluviométrica & Localização & Latitude(S) & Longitude(W) \\
\hline & Série Histórica & $22^{\circ} 08^{\prime}$ \\
2246057 & Camanducaia & $22^{\circ} 45^{\prime}$ & $4^{\circ} 25^{\prime}$ \\
D3-018 & Vargem & $22^{\circ} 54^{\prime}$ & 1974 a 2006 \\
D3-019 & Joanópolis & $22^{\circ} 58^{\prime}$ & $46^{\circ} 06^{\prime}$ a 2004 \\
D3-035 & Pedra Bela & $22^{\circ} 48^{\prime}$ & $46^{\circ} 27^{\prime}$ a 1993 \\
D3-054 & Joanópolis & $22^{\circ} 56^{\prime}$ & $46^{\circ} 16^{\prime}$ \\
E3-242 & Igaratá & $23^{\circ} 12^{\prime}$ & $46^{\circ} 09^{\prime}$ \\
\hline
\end{tabular}

Fonte: www.sigrh.sp.gov.br e hidroweb.ana.gov.br

Para o cálculo do fator L da RUSLE, utilizou-se o método proposto por Desmet \& Govers (1996), que foi desenvolvido para o cálculo de rampas não uniformes. $\mathrm{O}$ fator de declividade (S) foi obtido segundo o método de Wischmeier \& Smith (1978).

A fim de facilitar a discussão da potencialidade/ efetividade de cada cenário, para redução da erosão na sub-bacia das Posses, e compará-los de maneira relativa, utilizou-se o índice denominado Redução Relativa da Perda de Solo Anual (RRPS), de acordo com Mingoti (2009).

$$
R R=\left[1-\left(\frac{E_{i}-E_{F}}{E_{P}-E_{F}}\right)\right] \cdot 100
$$

em que RR é a redução relativa da perda de solo anual, \%; Ei, a erosão anual média para o i-ézimo cenário, $\mathrm{Mg} \mathrm{ha}^{-1}$ ano $^{-1}$; EF, a erosão anual média para o cenário que apresentou a menor perda de solo, $\mathrm{Mg}_{\mathrm{ha}} \mathrm{h}^{-1}$ ano-1; e EP, a erosão anual média para o cenário em que foi verificada a maior perda de solo, $\mathrm{Mg} \mathrm{ha}^{-1} \mathrm{ano}^{-1}$.

Empregando-se a mesma analogia do índice de RRPS, foi gerado outro índice, denominado de índice de Incremento Relativo de Área de Floresta (IRAF), objetivando comparar a RRPS em função do incremento de área de floresta. Na equação 3 é apresentada a metodologia para o cálculo do índice de IRAF.

$$
\operatorname{IRAF}=\left(\frac{\mathrm{AF}_{\mathrm{i}}-\mathrm{AF}_{1}}{\mathrm{AF}_{\mathrm{x}}-\mathrm{AF}_{1}}\right) \cdot 100
$$

em que IRAF é o incremento relativo de área de floresta, \%; $\mathrm{AF}_{\mathrm{i}}$, a área de floresta para o i-ézimo cenário, ha; $\mathrm{AF}_{1}$, a área de floresta no cenário 1, ha; e $\mathrm{AF}_{\mathrm{x}}$, a área de floresta para o cenário com maior RRPS, ha.

\section{RESULTADOS E DISCUSSÃO}

No quadro 3 são apresentados os valores estimados de perda de solo, RRPS e IRAF para os diferentes cenários estudados.
O cenário de uso e cobertura do solo em que se encontra a sub-bacia das Posses (cenário 1) é o que apresenta a maior perda de solo anual e, portanto, uma maior fragilidade em relação à conservação do solo e, consequentemente, para o provimento desse serviço ambiental. Isso se deve ao elevado grau de degradação da cobertura vegetal dessa sub-bacia (em sua grande parte, pastagens), à falta de APP e RL, e ainda, à presença de áreas bastantes declivosas, sem os devidos cuidados com relação às práticas conservacionistas.

Em relação à situação futura de uso e cobertura do solo na sub-bacia das Posses (cenário 10), verificase importante redução dos processos erosivos; isso decorre das práticas conservacionistas que foram nela implementadas, como a recomposição das APPs, RL e MT e a conservação do solo.

É possível verificar também (Quadro 3) o quanto de incremento relativo de área de floresta, aliada a outras práticas, é necessário para promover determinada RRPS, bem como a relevância das práticas conservacionistas para a redução da erosão do solo.

Comparando o cenário 9 (96\% de RRPS) com o cenário 11 (100\% de RRPS), verifica-se que para aumentar em $4 \%$ a RRPS foi necessário aumentar o IRAF em quase $17 \%$. Isso evidencia que, para as condições de pastagem conservada, APP e RL recompostas e alocação da floresta em áreas com declives iguais ou superiores a $30 \%$, a utilização de 100 \% da MT teve pouca relevância para a RRPS.

Os cenários 4 e 5 apresentam um contraste bastante interessante no que concerne à otimização da conservação do solo: ambos apresentaram RRPS de $57 \%$; no entanto, para o cenário 4, foi preciso aumentar a área de floresta em 71,2 \% em relação à situação inicial de uso e cobertura do solo na sub-bacia das Posses (cenário 1), ao passo que para o cenário 5 não houve necessidade de aumento da área de floresta para obtenção da mesma RRPS.

Nesses cenários, mais uma vez, ficou evidente a relevância da conservação da pastagem para a redução da erosão, pois, mesmo sem áreas de floresta, o fato de se conservar a pastagem implicou importante 
Quadro 3. Valores de perda de solo estimados com a RUSLE, RRPS e IRAF

\begin{tabular}{|c|c|c|c|c|c|c|c|}
\hline \multirow{2}{*}{ Cenário } & \multicolumn{4}{|c|}{ Situação } & \multirow{2}{*}{ Perda de Solo } & \multirow{2}{*}{ RRPS } & \multirow{2}{*}{ IRAF } \\
\hline & Pastagem & APP e RL & MT & Declividade & & & \\
\hline & & & & & $\mathrm{Mg} \mathrm{ha}^{-1} \mathrm{ano}^{-1}$ & - & - \\
\hline 1 & Degradada & Atual & Atual & não & 30,63 & 0 & 0 \\
\hline 2 & Degradada & Futura & Futura & $\geq 30 \%$ & 8,74 & 85 & 100 \\
\hline 3 & Degradada & Futura & Futura & $\geq 40 \%$ & 11,59 & 74 & 89,7 \\
\hline 4 & Degradada & Futura & $50 \%$ Futura & não & 16 & 57 & 71,2 \\
\hline 5 & Conservada & Atual & Atual & não & 15,84 & 57 & 0 \\
\hline 6 & Conservada & Atual & Futura & $\geq 30 \%$ & 8,04 & 88 & 62,6 \\
\hline 7 & Conservada & Atual & Futura & $\geq 40 \%$ & 11,27 & 75 & 39,4 \\
\hline 8 & Conservada & Atual & $50 \%$ Futura & $\geq 30 \%$ & 8,62 & 85 & 71,2 \\
\hline 9 & Conservada & Futura & Atual & $\geq 30 \%$ & 5,8 & 96 & 83,2 \\
\hline 10 & Conservada & Futura & Futura & não & 7,06 & 91 & 84,9 \\
\hline 11 & Conservada & Futura & Futura & $\geq 30 \%$ & 4,83 & 100 & 100 \\
\hline 12 & Conservada & Futura & Futura & $\geq 40 \%$ & 6,3 & 94 & 89,7 \\
\hline 13 & Conservada & Futura & $50 \%$ Futura & não & 8,68 & 85 & 54,3 \\
\hline 14 & Conservada & Futura & $50 \%$ Futura & $\geq 40 \%$ & 7,44 & 90 & 77,9 \\
\hline
\end{tabular}

APP: Área de Preservação Permanente; RL: Reserva Legal; MT: Mata de Topo; RRPS: Redução Relativa de Perda de solo; IRAF: Incremento Relativo de Área de Floresta.

redução de perda de solo. Isso indica que, em certos casos, outras práticas de conservação, que não o reflorestamento, podem ser bastante efetivas, o que corrobora os resultados observados por Dosskey (2001).

É importante observar que o fato de haver práticas voltadas à conservação da pastagem, a qual representa grande parte da área da sub-bacia das Posses (aproximadamente $80 \%$ ), além de promover benefícios importantes para a conservação do solo, pode ser mais um fator estimulador do aumento de renda para os produtores, uma vez que, com a pastagem conservada, há maior volume de biomassa e, consequentemente, possibilidade de maior densidade animal.

No caso da sub-bacia das Posses, onde a pecuária leiteira é uma das principais fontes de renda, a conservação da pastagem torna-se crucial, considerando que os produtores destinaram parte da área de suas propriedades para a implantação das práticas previstas no projeto "Conservador das Águas" e, por conseguinte, reduziram suas áreas para outras atividades; com a conservação da pastagem, poder-seia aumentar a densidade animal de modo a "compensar" essa redução de área. Além disso, ela manteria ainda a fonte de renda proveniente da atividade leiteira, o que, aliado aos PSA, proporcionaria ganho ainda maior para os produtores dessa sub-bacia, gerando benefícios tanto ambientais quanto sociais.

Analisando os cenários 8 e 13, pode-se verificar a importância das áreas de APP e RL e da alocação de florestas em áreas com declives iguais ou superiores a $30 \%$. Ambos os cenários apresentaram RRPS iguais (85\%), porém o cenário 8 com $71,2 \%$ de IRAF e o cenário 13 com 54,3\%, ou seja, 16,9\% a mais. Observa-se que para esses cenários a alocação de florestas em áreas com declives iguais ou superiores a $30 \%$ teria o mesmo efeito de recompor as áreas de APP e RL; contudo, a escolha de alocar florestas em áreas com declives iguais ou superiores a $30 \%$ (cenário 8) seria menos eficiente no que concerne à otimização da RRPS em função do IRAF.

Esses resultados corroboram os de Dosskey (2001), Schoonover et al. (2006), Lowrance \& Sheridan (2005) e Knight et al. (2010), que ressaltaram a importância da APP para a redução da produção de sedimentos, observando que os primeiros metros da zona ripária (próximas aos cursos d'água) são responsáveis por mais de 50 \% da remoção de sedimentos. Mingoti (2009) também verificou a tendência de que uma menor largura da APP pode proporcionar o mesmo efeito, ou efeito bem próximo, em relação à erosão anual de uma microbacia e ressaltou que, com a RL localizada ao longo da APP, obtêm-se melhores resultados para a redução da erosão anual.

Nos cenários 3 e 7 é possível observar, de outra perspectiva, a efetividade das práticas de conservação de solo adotadas. A RRPS para os dois cenários foi praticamente a mesma (75\%); entretanto, no cenário 3 a área de floresta teve de ser aumentada em 50,3\%, em relação ao cenário 7. Nesses cenários, é possível verificar que, quando se utiliza a MT em conjunto com a conservação das áreas de pastagem, obtém-se uma combinação mais efetiva do que o uso da MT, APP e RL com pastagens degradadas, considerando em ambos os cenários o reflorestamento de áreas com declives iguais ou superiores a $40 \%$.

No cenário futuro, previsto no projeto "Conservador das Águas" (cenário 10), conjuntamente com a implementação das práticas conservacionistas, foi necessário aumentar a área florestada em praticamente $85 \%$, a fim de obter redução de perda de solo de 91 \%, em relação ao cenário inicial. 
Comparando o cenário 10 com aquele que apresentou o maior potencial para redução de perda de solo (cenário 11), verifica-se que o IRAF de $15 \%$ (aproximadamente 114 ha a mais do que o cenário 10, que possui $736 \mathrm{ha}$ ) proporcionou apenas $9 \%$ de RRPS $\left(2,22 \mathrm{Mg} \mathrm{ha}^{-1} \mathrm{ano}^{-1}\right)$. Considerando que o incremento de benefício em relação à conservação do solo para esses cenários é relativamente pequeno, os tomadores de decisão poderiam optar pela alocação dessa área de floresta em outras sub-bacias, o que proporcionaria aumento marginal da RRPS, otimizando assim o benefício do provimento do serviço ambiental de conservação do solo.

Com a análise dos cenários apresentados, fica claro que, para obter reduções importantes de perda de solo, promovendo o provimento desse serviço ambiental, é importante que a bacia ou sub-bacia em questão seja analisada de uma forma integrada e que a implantação das práticas conservacionistas seja coordenada.

Verifica-se, ainda, que a redução de perda de solo não obedece a uma lógica linear em relação ao aumento das áreas de floresta, ou seja, a RRPS tem acréscimo decrescente em relação ao IRAF; em outras palavras, o fato de se aumentar a área de floresta não implica necessariamente aumento da redução de perda de solo, pois existem outras práticas que também exercem grande influência sobre essa variável.

Nesse sentido, é possível, considerando as demais práticas conservacionistas, maximizar a conservação do solo em função da área de floresta, como, por exemplo, em investimentos de capital; maximizar o benefício líquido direto (conservação do solo) em função dos recursos investidos (aumento de área de floresta).

$\mathrm{Na}$ figura 4, pode ser facilmente visualizada a relação entre o IRAF e a RRPS, onde se verifica que esta diminui à medida que o IRAF aumenta. Nesse contexto, uma vez que sejam apresentados os diferentes cenários ou estratégias possíveis de serem implementados em determinado projeto de PSA, em função do objetivo e dos recursos para este, o tomador de decisão poderá decidir entre os mais convenientes para o cumprimento das metas estabelecidas.

Verifica-se também que, para todos os cenários com pastagem conservada, a RRPS foi superior ou no mínimo igual ao IRAF, ao passo que para os cenários com pastagem degradada a RRPS foi sempre inferior ao IRAF. Isso significa que, quando não se opta pela conservação da pastagem em bacias onde esse uso é bastante expressivo, é necessário aumentar consideravelmente a área de floresta para obter RRPS maiores.

Observa-se ainda que ocorre interação entre a área de pastagem e o IRAF sobre a RRPS, pois, à medida que a área de floresta aumenta, consequentemente a de pastagem diminui, fazendo com que o efeito da pastagem sobre a RRPS seja mais atenuado com o aumento do IRAF. Em outras palavras, quando a área de floresta é pouco representativa na sub-bacia, a conservação da pastagem potencializa a RRPS e maximiza o provimento desse serviço ambiental.

$\mathrm{Na}$ figura 5, pode-se observar a RRPS em função da área total de floresta para cada cenário estudado.

Verifica-se que os cenários 6, 12 e 14 foram bastante efetivos para a RRPS, apresentando valores bem próximos, ou até mesmo superiores ao do cenário futuro previsto no projeto "Conservador das Águas" (cenário 10). Para o cenário 6, mesmo sem considerar a recuperação da APP e RL, o fato se ter a MT prevista no projeto, bem como áreas com declives acima de $30 \%$ ocupadas com floresta, implica valores de RRPS muito próximos ao do cenário futuro.

Vale destacar um aspecto interessante em relação ao cenário 6: mesmo com cerca de 170 ha de área de floresta a menos do que o cenário 10, apresentou reduções bastante importantes, o que salienta a relevância da localização das áreas de floresta e a recuperação das pastagens degradadas, como observam Mingoti (2009) e Inácio et al. (2007).

Constata-se também que, nos cenários 8, 2 e 13, a RRPS foi a mesma; contudo, a área de floresta dos cenários 2 e 13 foi maior do que a do cenário $8 \mathrm{em}$, respectivamente, 346,19 e 217,75 ha. Esses resultados indicam, de maneira bastante clara, que o reflorestamento de uma bacia ou sub-bacia hidrográfica de forma aleatória, sem uma análise conjunta e integrada dos diferentes fatores (solo, declividade, práticas conservacionistas, etc.) pode ser ineficiente, do ponto de vista de otimização, para o provimento do serviço ambiental de conservação do solo em função da área reflorestada.

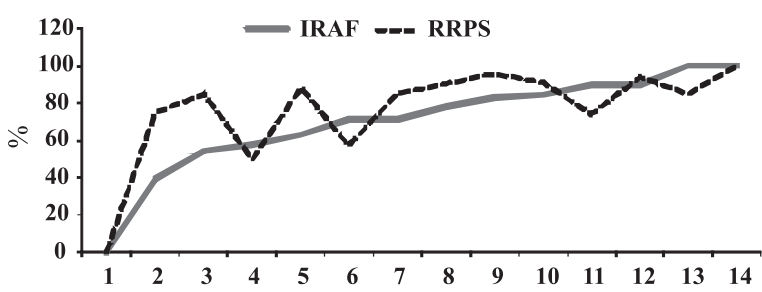

Figura 4. Redução relativa de perda de solo (RRPS) em função do incremento relativo de área de floresta (IRAF) para os diferentes cenários estudados.

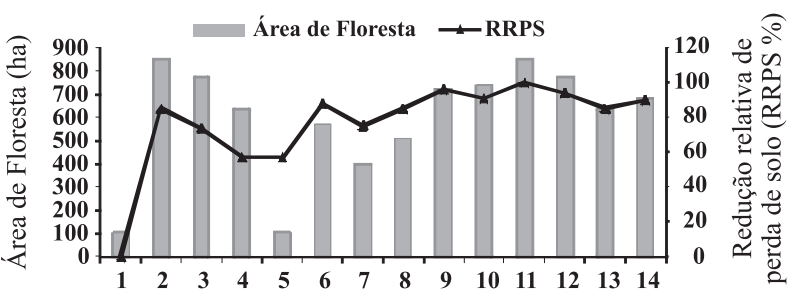

Figura 5. Redução relativa de perda de solo (RRPS) em função da área total de floresta para os diferentes cenários estudados. 
É importante observar que a análise dos diferentes cenários simulados foi feita de maneira comparativa e que não foi quantificado em campo o valor efetivo da erosão, o que limita as conclusões do trabalho. Salienta-se ainda a grande necessidade de trabalhos futuros que possam confrontar os dados de erosão simulados com os que serão levantados com o monitoramento da sub-bacia das Posses, visando ao refinamento das análises realizadas e ao avanço com as metodologias de avaliação e valoração dos programas de PSA.

\section{CONCLUSÕES}

1. As maiores Reduções Relativas de Perda de Solo ocorreram nos cenários com pastagem conservada, indicando que a otimização da conservação do solo pode ser feita adotando-se práticas de manejo conservacionista para a recuperação da pastagem.

2. Áreas de florestas com tamanhos iguais podem promover maior ou menor redução da perda de solo, dependendo de onde essa cobertura florestal esteja localizada na bacia hidrográfica, sendo um dos fatores mais relevantes para o provimento do serviço ambiental de conservação do solo nos projetos de Pagamentos por Serviços Ambientais a interação tamanho versus localização da cobertura florestal.

3. O cenário 11 foi o que apresentou o maior potencial para o provimento do serviço ambiental de conservação do solo, reduzindo em $25,8 \mathrm{Mg} \mathrm{ha}^{-1} \mathrm{ano}^{-1}$ a perda de solo simulada; no entanto, este cenário, juntamente com o cenário 2 , apresentou área de floresta superior à da área prevista no projeto "Conservador das Águas".

4. O projeto "Conservador das Águas" possui potencialidade de redução da perda de solo de $91 \%$; com apenas a recuperação da pastagem, essa potencialidade seria de $57 \%$.

\section{AGRADECIMENTOS}

À Prefeitura Municipal de Extrema e à The Nature Conservancy, pela grande contribuição com o banco de dados.

Ao Ministério da Ciência e Tecnologia (MCT), ao Conselho Nacional de Desenvolvimento Científico e Tecnológico $(\mathrm{CNPq})$ e à Fundação de Amparo à Pesquisa do Estado de São Paulo (FAPESP), pelo apoio financeiro a esta pesquisa, por meio do Instituto Nacional de Ciência e Tecnologia em Engenharia da Irrigação (INCTEI).

\section{LITERATURA CITADA}

AZEVEDO, T.S. Legislação e geotecnologias na definição das áreas de preservação permanente e das reservas legais: Aplicação à Bacia do Córrego das Posses, Município de Extrema - MG. Rio Claro, Universidade Estadual Paulista" Júlio de Mesquita Filho,”2008. 168p. (Tese de Doutorado)

BERTONI, J. \& LOMBARDI NETO, F. Conservação do solo. São Paulo, Ícone, 1999. 355p.

CHAVES, H.M.; BRAGA, B.; DOMINGUES, A.F. \& SANTOS, D.G. Quantificação dos benefícios e compensações do "Programa do Produtor de água" (ANA): I Teoria. R. Bras. Rec. Hídricos, 9:5-14, 2004.

DESMET, P.J.J. \& GOVERS, G. A GIS procedure for automatically calculating the USLE LS factor on topographically complex landscape units. J. Soil Water Conserv., 51:427-43, 1996.

DOSSKEY, M.G. Toward quantifying water pollution abatement in response to installing buffers on crop land. Environ. Manag., 28:577-598, 2001.

EXTREMA (cidade). Curso de Pagamentos por Serviços Ambientais - Projeto Conservador das Águas. Extrema: Secretaria do Meio Ambiente de Extrema, 2010. Disponível em: <http://www.infobibos.com/psa/>. Acesso em: 22 set. 2010 .

FIORIO, P.R.; DEMATÊ, J.A.M. \& SPAROVEK, G. Cronologia e impacto ambiental do uso da terra na microbacia hidrográfica do Ceveiro, em Piracicaba, SP. Pesq. Agropec. Bras., 35:671-679, 2000.

FOLEGATTI, M.V.; SÁNCHEZ-ROMÁN, R.M.; ZOLIN, C.A. \& GONZÁLEZ, A.M.G.O. Tranposição de água e disponibilidade hídrica das Bacias Hidrográficas dos rios Piracicaba, Capivarí e Jundiaí (BH-PCJ). In: CONGRESO LATINOAMERICANO Y DEL CARIBE DE INGENIERÍA AGRÍCOLA - CLIA, 9.; CONGRESSO BRASILEIRO DE ENGENHARIA AGRÍCOLA - CONBEA, 34., Vitória, 2010. Anais... Vitória, Sociedade Brasileira de Engenharia Agrícola, 2010. p.1-10.

GALVÃO, S.R.S.; SALCEDO, I.H. \& SANTOS, A.C. Frações de carbono e nitrogênio em função da textura, do relevo e do uso do solo na microbacia do agreste em Vaca Brava (PB). R. Bras. Ci. Solo, 29:955-962, 2005.

INÁCIO, E.S.B.; CANTALICE, J.R.B.; NACIF, P.G.S.; ARAUJO, Q.R. \& BARRETO, A.C. Quantificação da erosão em pastagem com diferentes declives na microbacia do Ribeirão Salomea. R. Bras. Eng. Agríc. Amb., 11:355-360, 2007

KNIGHT, K.W.; SCHULTZ, R.C.; MABRY, C.M. \& ISENHART, T.M. Ability of remnant riparian forests, with and without grass filters, to buffer concentrated surface runoff. J. Am. Water Res. Assoc., 46:311-322, 2010.

LISBOA, A.M. Zoneamento geoambiental aplicado ao planejamento da gestão ambiental e territorial do município de Colorado D’Oeste. Rio Claro, Universidade Estadual Paulista, 2008. 145p. (Tese de Doutorado) 
LOWRANCE, R. \& SHERIDAN, J.M. Surface runoff water quality in a managed three zone riparian buffer. J. Environ. Quality, 34:1851-1859, 2005.

MINGOTI, R. Produção de sedimentos em microbacias hidrográficas em função do relevo e da cobertura florestal. Piracicaba, Escola Superior de Agricultura "Luiz de Queiroz", Universidade de São Paulo, 2008. 101p. (Tese de Mestrado)

ORELLANA-GONZÁLEZ, A.M.G.; SÁNCHEZ-ROMÁN, R.M.; FOLEGATTI, M.V. \& ZOLIN, C.A. PCJ River Basins water availability caused by water diversion scenarios to supply metropolitan areas of São Paulo. Water Res. Manag., 25:1-16, 2011.

PIERANTONI, C.R. \& VIANNA, A.L. Avaliação de processo na implementação de políticas públicas: A implantação do Sistema de Informação e Gestão de Recursos Humanos em Saúde (SIG-RHS) no contexto das reformas setoriais. Physis, 13: 2003.

PESSOA, M.C.P.Y.; LUCHIARI, A.J.; FERNANDES, E.N. \& LIMA, M.A. Principais modelos matemáticos e simuladores utilizados para análise de impactos ambientais das atividades agrícolas. Jaguariúna, Embrapa/CNPMA, 1997. 83p. (Embrapa/CNPMA. Documentos, 8).

RENARD, K.G.; MEYER, L.D. \& FORSTER, G.R. Introduction and history. In: RENARD, K.G.; FORSTER, G.R.; WEESIES, G.A.; McCOOL, D.K. \& YODER, D.C., coord. Predicting soil erosion by water: a guide to conservation, planning with the revised universal soil loss equation (RUSLE). Washington, USDA/ARS, 1997. p.2-18.
SCHOONOVER, J.E.; WILLIARD, K.W.J.; ZACZEK, J.J.; MANGUN, J.C. \& CARVER, A.D. Agricultural sediment reduction by giant cane and forest riparian buffers. Water Air Soil Poll., 169:303-315, 2006.

SILVA, M.A.; LIMA, G.C.; SILVA, M.L.N.; FREITAS, D.A.F.; OLIVEIRA, A.H.; SANTOS, W.J.R.; PEREIRA, P.H.; SANTOS, D.G. \& VEIGA, F. Levantamento de solos e diagnóstico da degradação do solo e da água em função do uso. Lavras, Universidade Federal de Lavras, 2008. Disponível em: <http://www.ana.gov.br/produagua/>. Acesso em: 10 maio 2010

SOUTO, A.R. \& CRESTANA, S. Identificação das áreas potenciais de produção de sedimentos com o modelo AGNPS e técnicas de SIG em uma microbacia hidrográfica. R. Bras. Eng. Agríc. Amb., 4:429-435, 2000.

THOMAZ, E.L. Mudanças nas características físicas do topo do solo causadas por erosão laminar, em agricultura de subsistência no sistema de rodízio de terras - GuarapuavaPR. Geosul, 22:67-94, 2007.

WEILL, M.A.M. \& SPAROVEK, G. Estudo da erosão na microbacia do Ceveiro (Piracicaba, SP). I - estimativa das taxas de perda de solo e estudo de sensibilidade dos 97 fatores do modelo EUPS. R. Bras. Ci. Solo, 32:801-814, 2008.

WISCHMEIER, WH. \& SMITH, D.D. Predicting rainfail erosion loses: A guide to conservation planning. Washington, USDA, 1978. 58p. (Agriculture Handbook) 